\title{
Morpho-physiological traits associated with heat stress tolerance in tropical maize (Zea mays L.) at reproductive stage
}

\author{
Jewel Jameeta Noor ${ }^{1,2}$, M.T.Vinayan ${ }^{1}$, Shahid Umar ${ }^{2}$, Pooja Devi ${ }^{1}$, Muhammad Iqbal ${ }^{2}$, K. Seetharam, P.H. \\ Zaidi $^{1}$
}

${ }^{1}$ Asian Regional Maize Program, International Maize and Wheat Improvement Centre (CIMMYT), ICRISAT Campus, Hyderabad-502 324, India

${ }^{2}$ Hamdard University, Hamdardnagar, New Delhi, India

*Corresponding author: phzaidi@cgiar.org

\begin{abstract}
Heat stress resilience has emerged as an important trait in maize hybrids targeted for post-monsoon spring cultivation in large parts of South Asia and many other parts of the tropics. Selection based on grain yield alone under heat stress is often misleading, and therefore an approach involving stress-adaptive secondary traits along with grain yield could help in the development of improved, stable heat stress tolerant cultivars. We attempted to identify reliable and effective secondary traits associated with heat stress tolerance in tropical maize and sources of heat stress tolerant germplasm. A panel of 99 elite maize inbred lines representing the wider genetic diversity of tropical maize and a set of 58 elite hybrids were phenotyped under natural heat stress and optimal temperature for grain yield and 15 secondary traits including 10 morpho-physiological traits and 5 yield attributes. Evaluation under natural heat stress was done during the spring season by adjusting the planting date so that the complete reproductive stage (from tassel emergence to late grain filling) was exposed to heat stress. The optimal temperature trial was planted during the monsoon season with no exposure to heat stress at any crop stage. Heat stress significantly affected most of the observed traits. Among the traits studied two yield attributing traits, i.e.- ears per plant (EPP) and kernel per row (KPR), and three morpho-physiological traits, i.e.- chlorophyll content (CC), leaf firing (LF) and tassel blast (TB) were found to be the key secondary traits associated with grain yield under heat stress. In addition, low anthesis-silking internal (ASI) is an important trait that needs to be added in the index selection for heat stress tolerance. The study identified nine promising heat stress tolerant maize inbred lines with desirable secondary traits and grain yield under severe heat stress, which could be used as source germplasm in heat stress tolerance maize breeding program.
\end{abstract}

Keywords: Maize; Heat stress; Secondary traits; Climate change; Abiotic stress.

Introduction

In South Asia, millions of smallholders grow maize for their income and livelihood. While the demand for maize has significantly increased in recent years due to an array of factors, including changing diets and a rapidly growing poultry sector, average maize yield in South Asia is still only 2.9 tons per hectare ( $t / h a)$, about half of the world average maize yield (FAOSTAT, 2016). Since opportunities are limited for further expansion of maize cultivation areas, particularly in most of the developing countries, increase in maize supply to meet demands will have to be achieved through intensification of current maize production systems, such as expansion of maize cultivation areas during the Spring season in several countries of Asia (Dass et al., 2010).

Spring maize grown during the hot-summer months of the year (Feb-May) is invariably exposed to prolonged high temperature regimes (or heat stress) during most of the critical crop growth period, starting from the late vegetative stage until early grain filling. Also, during the monsoon season, the main maize crop season that accounts for over $70 \%$ of total maize area in South Asia, there is an increasing frequency of drought years combined with heat stress, which significantly limits productivity. Many climate-modeling studies suggest that high day- and night time temperatures will become more common in the future and may cause a tremendous environmental hurdle to global food production (Lobell et al., 2011a; Stebbins, 2011). Maize crop can survive brief exposures to high temperature. Exposure to temperatures above $35^{\circ} \mathrm{C}$ for a prolonged period is considered unfavourable for crop growth and beyond $40^{\circ} \mathrm{C}$, particularly during flowering and grain filling can have severe impact on grain yields (Commuri and Jones, 2001; Rincon and Lopez, 2006; Tesfaye et al., 2016).

Breeding for heat stress tolerance in maize had limited success, primarily because selection in stress tolerance breeding programs is often based on grain yield per se, which could be misleading in stressed trials owing to its low heritability estimates. Past studies have suggested the use of secondary traits along with grain yield in obtaining realistic genetic gains in breeding for tolerance to abiotic stresses (Bänziger and 
Laffitte., 1997 ; Araus et al., 2008; Ober et al., 2005; Ram et al., 2014). The approach of using secondary traits to complement phenotypic selection based on yield can improve selection response to a large extent, as heritability of some secondary traits remains high under stressed environment, and is often genetically correlated with yield under stress. Thus, breeding for stress tolerance can be complemented by identifying key secondary traits that are closely associated with yield under stressed environments (Ober et al., 2005). High heritability, significant association with grain yield under stressed environments and non-significant association of traits with grain yield under non-stressed environments are some of the important criteria of valuable secondary traits (Betran et al., 2003).

Several secondary traits associated with heat stress tolerance in maize have been identified, including leaf temperature kinetics (Shabala, 1996), leaf architecture net photosynthesis (Pn) at seedling stage (Yu et al., 2002; Karim et al., 2000), anther emergence (Schoper et al., 1987), and pollen viability (Frova et al., 1995) etc. However, their utility in stress breeding is not well established. Further, most of the research work on heat stress has focused on temperate maize whereas only limited information is available on tropical maize (Wilhelm et al., 1999; Monjardino et al., 2005). The present study aims at identifying effective secondary traits associated with heat stress tolerance in tropical maize, and source germplasm with desirable traits for use in breeding programs targeting heat stress resilient maize cultivars.

\section{Results}

\section{Variance and mean performance of inbreds and hybrids:}

Genotypic variance for all the traits in inbreds under heat stress and hybrids under optimal and heat stress showed significant variation (Table 1). The Genotype $x$ Environment (GXE) interaction also had highly significant variation for all the traits in inbreds and hybrids, except for chlorophyll content (CL), leaf firing (LF) and canopy temperature depression (CTD) in the inbreds. In general, genotypic variation in inbred lines for all the yield traits was relatively higher during year two. Variation for secondary traits was comparatively more in year one, except for anthesis date (AD), canopy temperature depression (CTD) and plant height (PH). In case of hybrids, except for kernels per row (KPR), cob girth (CG), anthesis date (AD), silking date (SD) and anthesis-silking interval (ASI), variance of all the other traits was drastically reduced under heat stress conditions. High broad-sense heritability ( $>55 \%$ ) was observed for all the traits in inbred lines in both the years. Heritability of traits in hybrids under optimal condition ranged from $48 \%$ to $84 \%$, whereas under heat stress, it ranged from $41 \%$ to $61 \%$ (Table 1).

Mean performance of inbred lines was consistent for most of the traits in both the years. However, flowering traits (AD and $\mathrm{SD}$ ) and two morpho-physiological traits (PH and $\mathrm{CC}$ ) were more affected due to heat stress during the second year (Table 1). In the case of hybrids, trial mean across environment exhibited drastic change under heat stress. The change was highest for GY followed by KPR, CC and PH, while EPP was least affected by heat stress. The range of GY of the hybrids was 25 fold higher under optimal conditions, and it reduced to four fold under heat stress (data not shown). In general, heat stress affected both $A D$ and $S D$, a more profound effect was observed on SD.

\section{Relation between grain yield and secondary traits}

Grain yield of inbreds under heat stress exhibited a significant positive correlation with all yield attributing traits and also with secondary traits viz,. AD, CC, CTD and INL. Other secondary traits (SD, ASI, SEN and LF) had significant negative correlation with grain yield under stress (Table 2). In the case of hybrids, grain yield exhibited a significant positive association with most of the observed traits except $\mathrm{CL}$ and SCMR under optimal conditions. However, only EPP and KPR maintained this association under heat stressed environment (Table 2). A changing trend in the direction of association was observed for two traits, i.e.- CG and INL. Traits such as $\mathrm{CL}$ and $\mathrm{CC}$ exhibited significant positive associations with grain yield under heat stressed environment, while these associations were non-significant under optimal conditions. The two secondary traits, CC and CTD, had significant positive and negative associations, respectively with grain yield under heat stress conditions.

\section{Principal component analysis}

Principle component analysis (PCA) was done to identify traits that complement yield under a heat stressed environment. Consistent results were observed for PCA during two years. PCA explained 36,35 and $34 \%$ of total variations during the first and second years, and across years, respectively (Table 3, Fig. 2). During both the years, PC-I explained the maximum percentage of variation. Observed traits contributed more than $20 \%$ of variation to either of the two PCs during both the years and across years. However, the highest contributing trait changed during the two years and across years. In year-1, ASI (37\%) and TB $(42 \%)$ were maximum contributing traits for two PCs, respectively, while KPR $(38 \%)$ and SD $(40 \%)$ were maximum contributors for two PCs during the second year.

Performance of grain yield of hybrids across environments was assessed using PCA. The average environment coordinate (AEC) view of GGE bi-plot explained mean yield performance and stability of genotypes. The highest yield across both the environments was recorded by the genotype HY42. Genotypes HY43 and HY47 also performed well across two environments. However, significant crossovers were also observed. For example- HY16 exhibited highly unstable performance for grain yield across two environments. Eighteen such genotypes with substantial crossover performance for GY (based on their instability indices) were selected to determine traits that could complement yield under heat stressed environment. Most of the measured traits showed a greater effect on the PC-I. The traits with high Eigen value of the PC-I were SD, AD, CC, KPR, CG and GY. Each trait contributed more than $25 \%$ of variation to the PC-I. However, SD contributed $42 \%$ of variation to the first PC. The main effects on the second component among the traits tested were $\mathrm{CL}, \mathrm{KPR}, \mathrm{CTD}, \mathrm{TB}, \mathrm{EPP}$ and INL. Each of these traits contributed more than $20 \%$ of variation to PC-II (Table 3 and Fig. 3).

Nine promising inbred lines were selected among different maturity groups on the basis of their performance across years under heat stress conditions (Table-4). Among these, 
the three best performing lines were INB 67, INB 14 and INB 39 with average grain yield of $1.01,0.85,0.71$ tons $\mathrm{ha}^{-1}$, respectively under heat stress. Selected inbred lines performed better in terms of their secondary traits associated with grain yield. All selected lines had $>5.0 \mathrm{~cm}$ $\mathrm{CL}$ and $>5.0 \mathrm{KPR},<64$ days $\mathrm{SD},>10$ score of $\mathrm{CC}$ and $<3$ score for $L F$ and $T B$.

\section{Discussion}

One of the major limitations of spring grown maize in Asian the tropics is prolonged high temperatures regimes $\left(>35^{\circ} \mathrm{C}\right)$, which often coincide with the reproductive growth stages that eventually affect maize crop yields. Selection for high grain yield has been a common criteria in maize breeding programs, however, the low heritability of grain yield under stress owing to the complex nature of the trait often limits significant selection gains (Edmeades et al., 1993). Significant genetic gains were reported in maize under abiotic stresses such as low nitrogen and drought by complementing grain yield with key secondary traits (Edmeades et al., 1998). Our study aimed at identifying key stress-adaptive secondary traits that could complement the selection for improved grain yield under heat stressed environment.

Significant genotypic variation was observed among maize inbred lines for most of the observed traits under heat stress across the two-year evaluations. The higher magnitude of genotypic variance for all the yield-attributing traits might be the result of exposure of genotypes to prolonged high temperatures from the vegetative to the reproductive crop growth phase (Fig 1) and their differential expression to such unfavourable conditions. The magnitude of response of the genotypes in optimal conditions is determined by the physiological determinants of grain yield like radiation, water use efficiency, metabolic processes, harvest index or biomass partitioning to reproductive organs (Passioura, 1996; Suwa et al., 2010). However, under heat stress, as a consequence of change in these physiological determinants, the overall responses of the genotype varied significantly in both seasons. Morpho-physiological traits for most of the genotypes did not differ substantially, suggesting relatively simple genetic determinants for these traits compared to the yield and yield attributes.

During year-1, the temperature was comparatively higher $\left(>38^{\circ} \mathrm{C}\right)$ for a prolonged period during the reproductive stage of the crop, which resulted in high variation among the genotypes for most of the secondary traits. Evaluation of hybrids under optimal and heat stressed environments revealed a similar trend in variation among the traits across the two seasons. However, the variation among trait values was more pronounced in hybrids as compared to the inbred lines because of the contrasting nature of the environmental conditions and/or due to the different genetic make-up of inbreds and hybrids.

Leaf firing, tassel blast and senescence are specific stress injuries on maize plants exposed to heat stress. Our study revealed a large variation among maize germplasm for these traits. Selected inbred lines were able to withstand the heat stress without significant tissue injuries (Table 4). In general, most of the hybrids exhibited the least of such visible stress injuries as compared to inbred lines, suggesting a different threshold for the injury or/and a probable coping mechanism in hybrids to overcome the increased production of free radicals and expression of oxidative stress enzymes under heat stress (Apel and Hirt, 2004).

Tissue injuries on active photosynthetic areas such as leaf firing and leaf senescence could drastically affect photosynthetic efficiency. These tissue injuries could be directly associated with reduced chlorophyll content and eventually with reduced grain yields and oxidative damage under heat stress (Tesfaye et al., 2016; Alam et al., 2017). Other important tissue injury reported in the current study was tassel blast, which could indirectly affect grain yield because pollen grains are highly susceptible as they lack heat shock proteins (HSPs) (Schoper et al., 1987) and low water potential under heat stress (Dupuis and Dumas, 1990) resulted in reduced availability of viable pollen grains. In general, heat stress advanced both male and female flowering, reduced PH and INL among genotypes. However, SD was more affected compared to $A D$, resulting in increased ASI that affected asynchrony between male and female flowers and eventually led to reproductive failure. In a determinant crop like maize the precursors of the reproductive stage are determined during the active vegetative phase or when the canopy size is defined (Nesmith and Ritchie, 1992; Uhart and Andrade, 1995). Delay in the development of reproductive organs might be the result of reduced cell division and cell elongation processes due to reduced supply of photosynthates and carbohydrate metabolism during the active vegetative growth stage (Suwa et al., 2010). The current study revealed a significant negative association of CC with levels of leaf injury (LE and SEN) and significant association with GY under heat stress (Fig. 2). Similar findings in maize have also been reported by Liu and Huang (2000). Broad-sense heritability of CC, LF and TB under heat stress for both inbred lines and hybrids were higher and therefore these traits could be considered important secondary traits in the selection for heat stress tolerance. Chlorophyll content is a known important trait associated with grain yield under abiotic stresses, such as under drought stressed wheat (Betran et al., 2003) and sorghum (Duncan et al. 1981, Rosenow and Clark 1981, Borrell et al. 2000).

The magnitude of association of flowering traits with GY was higher for inbred lines under heat stress. However, these associations were non-significant in the case of hybrids. While this observation might rule out the use of flowering traits as an important secondary trait for grain yield under heat stress, this conclusion may not be valid as non-significant association does not necessarily mean that the traits are not biologically related, and might probably be a result of decreased phenotypic variation among the hybrids for this trait under stress, confounding the estimation of genetic effects (Ober et al., 2005). Further, several breeding programs have indicated the effectiveness of flowering traits, especially ASI, in the selection for tolerance to abiotic stress such as drought (Bänziger et al., 1999). Another important feature identified for heat stress in maize was its effect on canopy temperature (Cairns et al., 2012). Certain genotypes are better equipped in maintaining their canopy temperature by increasing rate of transpiration. This trait has been used as an effective measure in improving drought and heat stress tolerance in several crops (Kumari et al., 2007). However, limited information is available about this trait in maize. Our study suggested significant variation among genotypes and a strong association of this trait with grain yield under heat stress. 


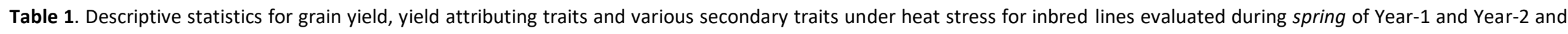
hybrids under optimal and heat stress during spring and Kharif seasons in Hyderabad, India.

\begin{tabular}{|c|c|c|c|c|c|c|c|c|c|c|c|c|c|c|c|}
\hline \multirow{3}{*}{ Traits } & \multicolumn{7}{|c|}{ Variance due to Genotypic and Genotype x Environment } & \multicolumn{4}{|l|}{ Mean } & \multicolumn{4}{|c|}{ Broad-sense heritability $\left(h^{2}, \%\right)$} \\
\hline & \multicolumn{3}{|c|}{ Inbred } & \multicolumn{4}{|c|}{ Hybrid } & \multicolumn{2}{|l|}{ Inbred } & \multicolumn{2}{|l|}{ Hybrid } & \multicolumn{2}{|c|}{ Inbred } & \multicolumn{2}{|c|}{ Hybrid } \\
\hline & $\begin{array}{l}\text { Year-1 } \\
\left(\sigma^{2} g\right)\end{array}$ & $\begin{array}{l}\text { Year-2 } \\
\left(\sigma^{2} g\right)\end{array}$ & $\sigma^{2}$ gxe & $\begin{array}{l}\text { Optimal } \\
\left(\sigma^{2} g\right)\end{array}$ & $\begin{array}{l}\text { Heat } \\
\left(\sigma^{2} g\right)\end{array}$ & stress & $\sigma^{2}$ gxe & $\begin{array}{l}\text { Heat } \\
\text { Year-1 }\end{array}$ & $\begin{array}{l}\text { Heat } \\
\text { Year-2 }\end{array}$ & Optimal & Heat & Year-1 & Year-2 & Optimal & Heat \\
\hline \multicolumn{16}{|c|}{ Yield and yield attributes } \\
\hline $\mathrm{GY}\left(\mathrm{t} \mathrm{ha} \mathrm{a}^{-1}\right)$ & $0.11^{\mathrm{a}}$ & $0.30^{\mathrm{a}}$ & $0.18^{b}$ & $3.69^{\mathrm{a}}$ & $0.39^{\mathrm{a}}$ & & $0.13^{b}$ & 0.40 & 0.33 & 6.89 & 1.86 & 66 & 76 & 58 & 52 \\
\hline EPP (\#) & $0.12^{\mathrm{a}}$ & $0.12^{\mathrm{a}}$ & $0.12^{\mathrm{a}}$ & $0.007^{\mathrm{a}}$ & $0.02^{\mathrm{a}}$ & & $0.11^{\mathrm{a}}$ & 0.43 & 0.41 & 0.88 & 0.69 & 68 & 73 & 48 & 53 \\
\hline KPR (\#) & $30.46^{a}$ & $56.59^{a}$ & $43.73^{b}$ & $7.64^{a}$ & $14.27^{\mathrm{a}}$ & & $52.13^{\mathrm{a}}$ & 7.22 & 7.72 & 36.62 & 22.13 & 87 & 89 & 52 & 61 \\
\hline KRPC (\#) & $10.20^{\mathrm{a}}$ & $16.40^{\mathrm{a}}$ & $9.81^{b}$ & $1.81^{a}$ & $1.04^{\mathrm{a}}$ & & $16.38^{\mathrm{a}}$ & 6.24 & 6.04 & 15.37 & 14.08 & 83 & 90 & 73 & 54 \\
\hline $\mathrm{CL}(\mathrm{cm})$ & $4.86^{\mathrm{a}}$ & $8.01^{a}$ & 7.34 & $6.02^{\mathrm{a}}$ & $0.44^{\mathrm{a}}$ & & $6.74^{\mathrm{a}}$ & 6.31 & 8.79 & 14.24 & 11.34 & 61 & 62 & 84 & 41 \\
\hline $\mathrm{CG}(\mathrm{cm})$ & $1.88^{b}$ & $4.57^{\mathrm{a}}$ & $4.06^{b}$ & $0.55^{\mathrm{a}}$ & $1.43^{\mathrm{a}}$ & & $2.02^{a}$ & 4.69 & 7.34 & 16.90 & 13.33 & 55 & 69 & 77 & 41 \\
\hline \multicolumn{16}{|c|}{ Secondary traits } \\
\hline AD (days) & $36.09^{a}$ & $39.33^{\mathrm{a}}$ & $57.41^{\mathrm{a}}$ & $13.05^{\mathrm{a}}$ & $14.74^{\mathrm{a}}$ & & $21.49^{a}$ & 45.1 & 41.4 & 51.2 & 42.3 & 87 & 87 & 91 & 88 \\
\hline SD (days) & $29.6^{a}$ & $20.09^{a}$ & $37.94^{\mathrm{a}}$ & $13.22^{\mathrm{a}}$ & $17.80^{\mathrm{a}}$ & & $15.60^{\mathrm{a}}$ & 51.3 & 48.2 & 52.4 & 48.4 & 82 & 69 & 91 & 88 \\
\hline ASI (days) & $122.9^{\mathrm{a}}$ & $89.44^{\mathrm{a}}$ & 104.08 & $0.69^{a}$ & $1.80^{\mathrm{a}}$ & & $97.33^{\mathrm{a}}$ & 6.2 & 12.3 & 1.2 & 6.1 & 79 & 69 & 64 & 57 \\
\hline SEN (score) & $0.01^{a}$ & $0.01^{a}$ & $0.01^{\mathrm{a}}$ & - & $0.00^{\mathrm{a}}$ & & $0.006^{\mathrm{a}}$ & 0.24 & 0.42 & - & 1.7 & 72 & 57 & - & 54 \\
\hline LF (score) & $15.67^{\mathrm{a}}$ & $7.45^{\mathrm{a}}$ & 9.28 & - & $4.83^{a}$ & & $11.58^{\mathrm{a}}$ & 3.21 & 4.73 & - & 15.1 & 90 & 80 & - & 93 \\
\hline TB (score) & $16.97^{\mathrm{a}}$ & $9.70^{a}$ & $13.31^{\mathrm{b}}$ & - & $0.90^{\mathrm{a}}$ & & $11.30^{\mathrm{a}}$ & 2.54 & 5.02 & - & 1.3 & 95 & 79 & - & 88 \\
\hline $\mathrm{CTD}\left({ }^{\circ} \mathrm{C}\right)$ & $1.66^{\mathrm{a}}$ & $2.47^{a}$ & 2.23 & - & $0.36^{\mathrm{a}}$ & & $2.04^{b}$ & -5.46 & -5.44 & - & 1.4 & 55 & 56 & - & 27 \\
\hline CC (SPAD) & $81.59^{a}$ & $26.44^{a}$ & $57.35^{a}$ & $50.32^{a}$ & $21.33^{a}$ & & $48.33^{a}$ & 23.88 & 17.14 & 30.2 & 24.0 & 62 & 58 & 53 & 55 \\
\hline $\mathrm{PH}(\mathrm{cm})$ & $392.2^{\mathrm{a}}$ & $428.35^{a}$ & $409.92^{a}$ & $329.90^{a}$ & $184.05^{a}$ & & $5.83^{b}$ & 139.8 & 94.3 & 253.3 & 193.2 & 77 & 74 & 75 & 63 \\
\hline INL (cm) & $4.12^{\mathrm{a}}$ & $1.86^{\mathrm{a}}$ & $3.60^{\mathrm{a}}$ & $0.42^{\mathrm{a}}$ & $0.51^{\mathrm{a}}$ & & $2.38^{\mathrm{a}}$ & 8.1 & 4.5 & 14.1 & 10.9 & 77 & 70 & 33 & 33 \\
\hline
\end{tabular}

GY-Grain yield, EPP-Ears per plant, KPR-Kernels per row, KRPC-No. of kernel rows per cob, CL-Cob length, CG-Cob girth, AD-Days to 50\% anthesis, SD-Days to 50\% silking, ASI-Anthesis siln
SPAD chlorophyll meter reading, PH-Plant height, INL-Inter-nodal length, $\sigma^{2}$-Genotypic variance, $\sigma^{2}$ gxe-Genotypex environment variance, ${ }^{a}$ - significant at $1 \%$ level, ${ }^{b}$-significant at $5 \%$ level 

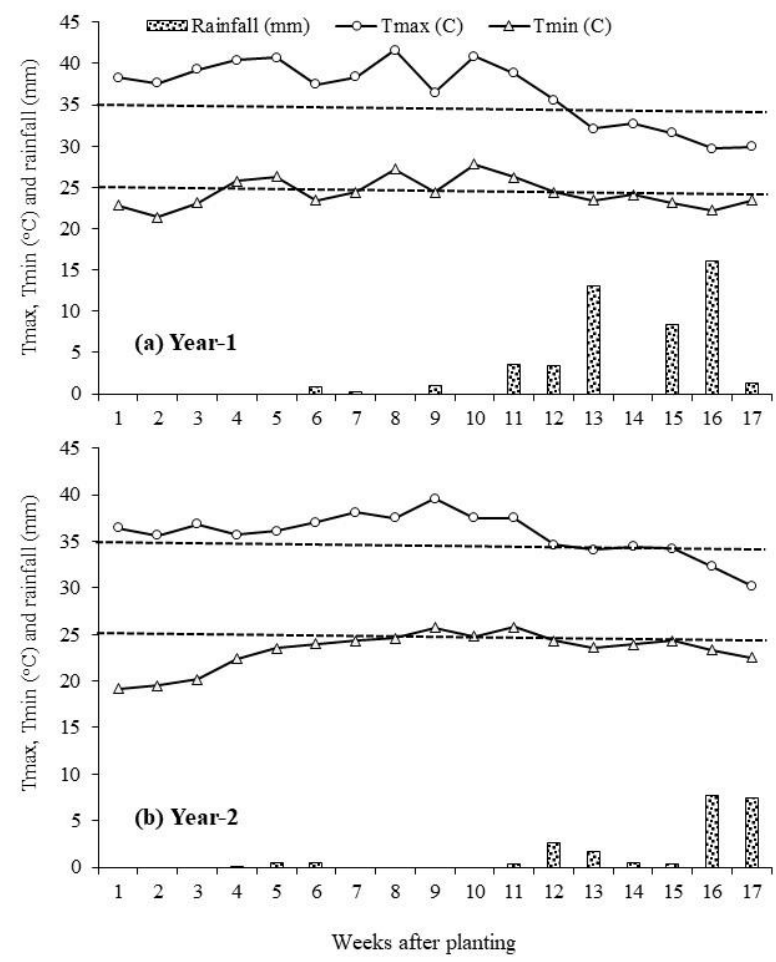

Fig 1. Weather data, including maximum temperature (Tmax), minimum temperature (Tmin) and rainfall during the experimental period in two consecutive years at CIMMYT experimental farm, ICRISAT campus Hyderabad India.

Table 2. Correlation of grain yield with yield attributing traits and various secondary traits under heat stress for inbred lines (pooled data of two years) and hybrids under optimal and heat stress at Hyderabad, India.

\begin{tabular}{llll}
\hline & $\begin{array}{l}\text { Inbreds under heat } \\
\text { stress }\end{array}$ & Hybrid & \\
\cline { 2 - 3 } & $\begin{array}{l}\text { Pooled } \\
\text { (Year-1 and 2) }\end{array}$ & Optimal & Heat stress \\
\hline Yield traits & & & \\
\hline EPP (\#) & $0.58^{* *}$ & $0.32^{* *}$ & $0.31^{* *}$ \\
KPR (\#) & $0.44^{* *}$ & $0.41^{* *}$ & $0.22^{*}$ \\
KRPC (\#) & $0.31^{* *}$ & $0.21^{*}$ & -0.01 \\
CL (cm) & $0.33^{* *}$ & -0.18 & $0.30^{* *}$ \\
CG (cm) & $0.23^{* *}$ & $0.67^{* *}$ & $-0.28^{*}$ \\
\hline Secondary traits & & & \\
\hline AD (days) & $0.18^{*}$ & $0.69^{* *}$ & -0.03 \\
SD (days) & $-0.36^{* *}$ & $0.73^{* *}$ & -0.06 \\
ASI (days) & $-0.25^{* *}$ & $0.21^{*}$ & -0.09 \\
SEN (score) & $-0.35^{* *}$ & - & 0.09 \\
LF (score) & $-0.17^{*}$ & - & 0.06 \\
TB (score) & 0.09 & - & -0.13 \\
CTD ( $\left.{ }^{\circ} \mathrm{C}\right)$ & $0.17^{*}$ & - & $-0.21^{*}$ \\
CC (SPAD) & $0.46^{* *}$ & -0.02 & $0.23^{*}$ \\
PH (cm) & 0.04 & $0.78^{* *}$ & -0.16 \\
INL (cm) & $0.25^{* *}$ & $0.26^{*}$ & $-0.31^{* *}$ \\
\hline
\end{tabular}

**significant at $1 \%$ level, *significant at $5 \%$ level

EPP-Ears per plant, KPR-Kernels per row, KRPC- No. of kernel rows per cob, CL-Cob length, CG-Cob girth, AD-Days to 50\% anthesis, SD-Days to 50\% silking, senescence, LF- Leaf firing, TB-Tassel blast, CTD-Canopy temperature depression, CC-SPAD chlorophyll meter reading, PH-Plant height, INL-Inter-nodal length. 


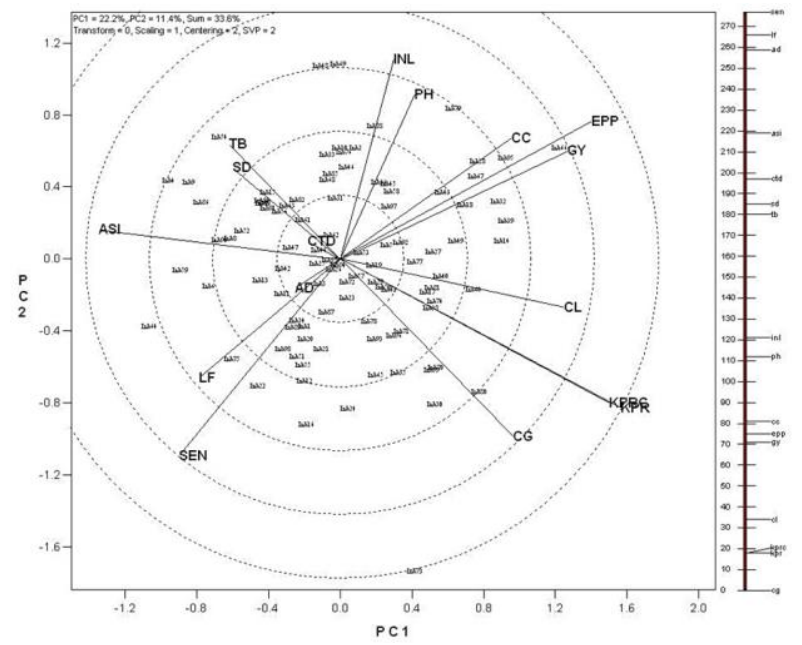

Fig 2. Principal component analysis for maize inbred lines depicting correlation of secondary traits with grain yield under heat stress (pooled data of two years). GY-Grain yield, EPP-Ears per plant, KPR-Kernels per row, KRPC- No. of kernel rows per cob, CL-Cob length, CG-Cob girth, AD-Days to 50\% anthesis, SD-Days to 50\% silking, ASI-Anthesis silking interval, SEN-Leaf senescence, LF- Leaf firing, TB-Tassel blast, CTD-Canopy temperature depression, CC-SPAD chlorophyll meter reading, PH-Plant height, INL-Inter-nodal length

Table 3. Principle component analysis of various yield attributing and morpho-physiological traits in maize inbred lines during spring season of year-1, year- 2 and across years, and maize hybrids (with more than 0.65 instability indices) during spring season of year- 1 under heat stress using correlation matrix .

\begin{tabular}{|c|c|c|c|c|c|c|c|c|}
\hline \multirow{3}{*}{ Traits } & \multicolumn{6}{|c|}{ Inbred lines } & \multirow{2}{*}{\multicolumn{2}{|c|}{$\begin{array}{l}\text { Hybrids } \\
\text { Year-1 } \\
\end{array}$}} \\
\hline & \multicolumn{2}{|c|}{ Year-1 } & \multicolumn{2}{|c|}{ Year-2 } & \multicolumn{2}{|c|}{ Across } & & \\
\hline & $\mathrm{PCI}$ & PCII & $\mathrm{PCI}$ & PCII & $\mathrm{PCI}$ & PCII & $\mathrm{PCI}$ & PC II \\
\hline Eigen values & 3.6 & 2.2 & 4.1 & 2.1 & 3.7 & 1.9 & 4.9 & 2.4 \\
\hline Explained Variability (\%) & 21.8 & 13.9 & 25.0 & 10.2 & 22.2 & 11.4 & 37.2 & 15.3 \\
\hline Cumulative & 21.8 & 34.7 & 25.0 & 35.2 & 22.2 & 34.6 & 37.2 & 52.5 \\
\hline Yield_traits & \multicolumn{8}{|c|}{ Eigen vectors } \\
\hline $\mathrm{GY}\left(\mathrm{t} \mathrm{ha}^{-1}\right)$ & 0.35 & 0.16 & 0.28 & -0.13 & -0.04 & -0.38 & -0.26 & 0.25 \\
\hline EPP (Nos) & 0.18 & 0.35 & 0.27 & -0.33 & 0.31 & 0.21 & -0.08 & 0.23 \\
\hline KPR (Nos) & 0.32 & -0.07 & 0.38 & 0.27 & 0.37 & 0.00 & -0.33 & 0.30 \\
\hline KRPC (Nos) & 0.25 & -0.10 & 0.36 & 0.25 & 0.36 & -0.00 & 0.07 & 0.38 \\
\hline $\mathrm{CL}(\mathrm{cm})$ & 0.30 & 0.10 & 0.29 & 0.22 & 0.07 & 0.22 & -0.06 & 0.44 \\
\hline CG $(\mathrm{cm})$ & 0.17 & -0.04 & 0.30 & 0.33 & 0.29 & 0.11 & 0.30 & 0.16 \\
\hline \multicolumn{9}{|l|}{ Secondary traits } \\
\hline AD (days) & -0.07 & -0.41 & -0.06 & -0.19 & 0.20 & 0.00 & 0.40 & -0.03 \\
\hline SD (days) & -0.17 & -0.39 & -0.19 & 0.40 & -0.27 & -0.32 & 0.41 & -0.06 \\
\hline ASI (days) & -0.37 & 0.27 & -0.23 & 0.12 & -0.32 & 0.29 & 0.24 & -0.14 \\
\hline SEN (score) & -0.24 & 0.03 & -0.05 & -0.28 & -0.13 & 0.48 & 0.10 & -0.07 \\
\hline LF (score) & -0.23 & 0.30 & -0.23 & 0.37 & -0.19 & 0.39 & 0.08 & 0.11 \\
\hline TB (score) & -0.30 & 0.42 & 0.28 & -0.12 & 0.23 & -0.09 & -0.15 & -0.25 \\
\hline CTD $\left({ }^{\circ} \mathrm{C}\right)$ & 0.02 & 0.08 & 0.15 & 0.08 & 0.34 & 0.18 & 0.20 & 0.38 \\
\hline $\mathrm{CC}$ & 0.29 & 0.10 & -0.24 & 0.09 & -0.22 & 0.22 & -0.36 & -0.15 \\
\hline $\mathrm{PH}(\mathrm{cm})$ & 0.10 & 0.21 & 0.01 & 0.15 & -0.04 & 0.14 & 0.28 & 0.16 \\
\hline INL (cm) & 0.04 & 0.11 & 0.18 & 0.11 & 0.10 & -0.01 & -0.03 & 0.22 \\
\hline
\end{tabular}

PC I- Principal component I, PC II- Principal component II, GY-Grain yield. EPP-Ears per plant, KPR-Kernels per row, NKR- No. of kernel rows per cob, CL-Cob length, CG-Cob girth, AD- Days to 50\% anthesis, SD-Days to 50\% silking, ASI-Anthesis silking interval, SEN- Leaf senescence, LF- Leaf firing, TB-Tassel blast, CTD-Canopy temperature depression, CC- chlorophyll content, PH-Plant height, INL-Inter-nodal length, PC I-Principal component I, PC II- Principal component II. 


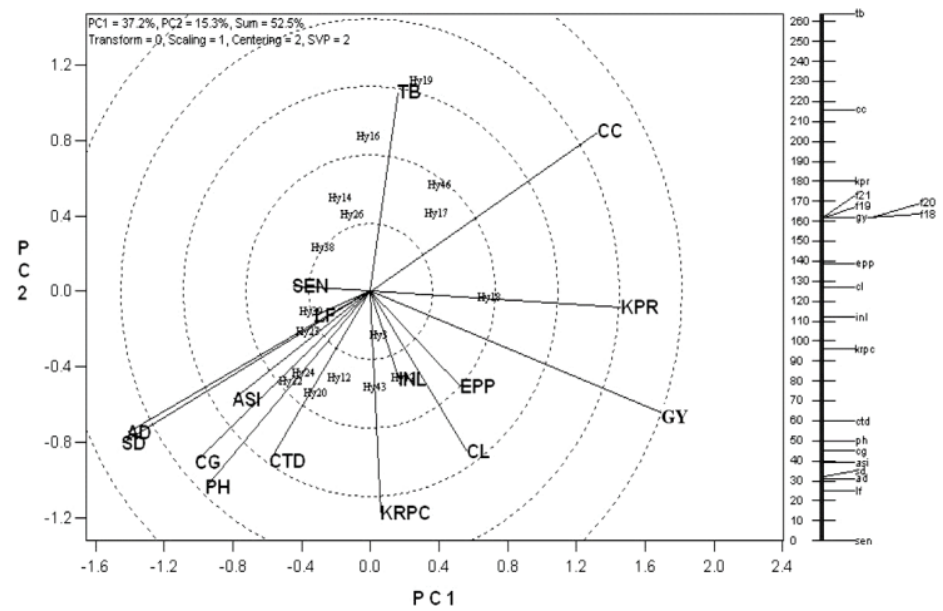

Fig 3. Principal component analysis for maize hybrid traits affecting yield under heat stress (selected 18 hybrids showing more than 0.65 stability index).GY-Grain yield, EPP- Ears per plant, KPR-Kernels per row, KRPC- No. of kernel rows per cob, CL-Cob length, CGCob girth, AD-Days to 50\% anthesis, SD-Days to 50\% silking, ASI- Anthesis silking interval, SEN- Leaf senescence, LF- Leaf firing, TBTassel blast, CTD-Canopy temperature depression, CC-SPAD chlorophyll meter reading, PH-Plant height, INL-Inter-nodal length.

Table 4. Performance of nine best inbred lines for different traits associated with grain yield under flowering stage heat stress (pooled data of two years trials during spring season at Hyderabad, India).

\begin{tabular}{|c|c|c|c|c|c|c|c|}
\hline Line Code & Genotype & GY $\left(\right.$ tha $\left.^{-1}\right)$ & $\mathrm{CL}(\mathrm{cm})$ & KPR (\#) & SD (days) & LF (1-5 scale) & $\begin{array}{ll}\text { TB } & (1-5 \\
\text { scale }) & \\
\end{array}$ \\
\hline INB14 & CA14502-BBB-2-BBB & 0.85 & 8.8 & 10.8 & 57.0 & 1.9 & 3.3 \\
\hline INB27 & CA14514-B-3-B-2-BB & 0.33 & 9.0 & 7.4 & 62.5 & 2.3 & 1.4 \\
\hline INB28 & CA14701-BB-1-BB & 0.59 & 7.9 & 9.3 & 63.5 & 2.8 & 3.1 \\
\hline INB32 & CM-117-3-2-1-1-1-1-1-1-BB & 0.38 & 9.3 & 10.9 & 63.0 & 1.5 & 1.4 \\
\hline INB39 & CML291-1-BB & 0.71 & 9.5 & 13.3 & 62.5 & 2.7 & 3.0 \\
\hline INB49 & CML421-2-BB & 0.52 & 8.5 & 6.6 & 62.0 & 2.0 & 2.3 \\
\hline INB67 & DTPWC9-F137-3-1-2-2-1-2-2-B & 1.01 & 11.8 & 13.2 & 61.0 & 2.6 & 3.6 \\
\hline INB74 & DTPYC9-F15-3-1-1-3-2-1-2-B & 0.33 & 4.9 & 6.6 & 60.0 & 1.5 & 3.0 \\
\hline INB78 & G18SeqC5F19-1-2-1-2-2-B & 0.41 & 6.5 & 5.4 & 61.0 & 3.0 & 1.6 \\
\hline
\end{tabular}

However, repeatability of the trait in inbred trials was moderate and for hybrid trials under heat stress it was low, indicating (i) a substantial influence of the environment on estimation of the trait and/or (ii) differential expression of the trait due to interaction with other environmental factors. CTD measurements are highly affected by irradiance, wind speed, humidity, vapour pressure deficit and time of measurement (Balota et al., 2007; Ram et al., 2014).

Several secondary traits have a direct or indirect effect on grain yield via yield attributing traits. Among the yield attributing traits, a significant reduction in average EPP was observed under heat stress, suggesting an increase in the frequency of barrenness due to high temperature. Cob architecture including CL, CG, KPR and KRPC are important contributors to grain yield in maize. Significant reduction was observed in most of these traits under heat stress, except for KRPC in hybrids suggesting a strong genetic constitution for this trait. While the performance of most hybrids was skewed towards the lower value for these traits, some entries exhibited a similar number of kernels per row across environments. This might be because different vegetative and reproductive organs undergo active growth at the same stage, which results in strong competition among them for assimilates. Imbalance in distribution of assimilates might be a cause for negative effects on yield attributing traits
(Rattalino et al., 2011). While variation for these traits was low for hybrids, the association of this trait with grain yield under stress was strong and significant for inbred lines and hybrids across environments, suggesting their important contribution in grain yield under stress. Our results are in agreement with previous findings where negative effects of high temperatures on cob growth rate and reduced biomass partitioning to ear was reported (Cicchino et al., 2010a; Cicchino et al., 2010b; Rattalino et al., 2011). A number of factors such as pollen viability, receptivity of silk, increased frequency of kernel abortion, decreased cell division in endosperm, reduced sink capacity of developing kernels, reduced starch synthesis, increased soluble sugar accumulation duration, kernel development and enzyme activities could be responsible for reduction in KPR under heat stress (Duke and Doehlert, 1996; Hunter et al., 1977; Singletary et al., 1994, Alam et al., 2017). All the yieldattributing traits exhibited significant positive association with GY during two years of study; however results varied for CG among inbred lines and hybrids. PCA presented similar results for hybrids and inbred lines exhibiting strong positive association for EPP, KPR, KRPC and CL with GY (Figs. 2 and 3). High heritability estimates were observed for EPP and KPR for inbred lines as well as hybrids, which suggest that these are important traits in selection indices for breeding programs 
targeting heat stress tolerance. Among yield attributing traits, EPP and KPR were identified as prominent candidates for the heat stress selection index. This is based on variations explained by the variables considered in this trait, their association with GY, repeatability during two years with inbred lines and hybrids under stressed environments, their expression and ease of scoring. Apart from these, weightage need to be given to heat stress specific secondary traits, such as CC, LF and TB, which were indirect determinants of stress tolerance through balancing the physiological mechanism to produce yield.

\section{Materials and Methods}

\section{Plant materials}

A total of 99 maize inbred lines from International Maize and Wheat Improvement Centre (CIMMYT); were evaluated, along with check entry (INB-55) one of the widely used CIMMYT maize lines (CML) in Asia region, for two consecutive years (2011 and 2012) under natural heat stress during the spring season at the International Crops research institute for semiarid tropics (ICRISAT) campus, Patancheru, Telangana, India $\left(17^{\circ} 30^{\prime} \mathrm{N} ; 78^{\circ} 16^{\prime} \mathrm{E} ; 549 \mathrm{masl}\right)$. The inbred lines were carefully selected elite lines representing a wider diversity of lowland tropical maize germplasm from Asia, Latin America and SubSaharan Africa. The major part of the study material constituted elite CIMMYT lines, including 31 lines from the CIMMYT-Asia maize program, 34 globally released CMLs for low-land tropics, 14 lines derived from a lowland tropical maize population P31C4, and 9 lines from a drought tolerant white (DTPW) population improved for drought for nine cycles of recurrent selection. Other lines involved in the study included three lines from Pool16 BNSequia, an early maturing white population improved for drought as well as low nitrogen tolerance, two lines from G18 Sequia, an early maturing yellow population improved for drought tolerance and one line each from La Posta SequiaC7, P147, Suwan-1, Indian maize program, EW-DMR and P31-DMR, two Asian maize populations improved for downy mildew resistance. The lines were evaluated for heat stress tolerance in replicated trials along with a heat tolerant check line - CML427. Apart from elite tropical lines, a set of 58 single cross hybrids including 51 popular commercial hybrids in India from seed companies and 7 elite hybrids from CIMMYT were evaluated under natural heat stress during spring and under optimal temperature conditions during monsoon (Kharif) season.

\section{Trial and stress management:}

All the trials were conducted at the ICRISAT campus, Hyderabad, India in carefully selected precision fields with vertisol soil with $\mathrm{pH}$ 7.6. Planting time for the spring season trials was adjusted so that most parts of the reproductive stage, including flowering and early grain filling, coincided with high day temperature regimes (Tmax close to $40^{\circ} \mathrm{C}$ ). Based on weather data for past five years during spring season, the third week of March was chosen as a suitable planting time and the crop reached reproductive stage during the first fortnight of May, when temperature was at its peak in Hyderabad. During both the years, the targeted crop stages were exposed to high temperature regimes, as both maximum (Tmax) and minimum temperatures (Tmin) were above the threshold limit, i.e. $35^{\circ} \mathrm{C}$ and $25^{\circ} \mathrm{C}$, respectively during most of the active crop growth and reproductive stages. During year-1, the vegetative and reproductive phases of the crop (from 28 to 56 DAS) were exposed to temperature ranging between $37.5^{\circ} \mathrm{C}$ and $41.6^{\circ} \mathrm{C}$, whereas during year-2, the same stages of the crop was exposed to temperatures ranging from 35.7 to $38.1^{\circ} \mathrm{C}$ (Fig. 1 ). During both the years, the active vegetative growth phase and reproductive stage were mostly free from any significant rainfall. Hybrid trials during monsoon season were planted at the recommended planting time, i.e. after the onset of the first monsoon rains, and most of the crop stage, including the reproductive stage was free from exposure to high temperature regimes.

Trials were laid out using $\alpha$-lattice design (Patterson et al., 1978) with two replications. Each plot was planted in $4 \mathrm{~m}$ long rows, with plant-to-plant and row-to-row spacing $75 \mathrm{~cm}$ and 20 $\mathrm{cm}$, respectively. Recommended agronomic management practices were followed to optimize crop growth and development, and trials were kept free from any abiotic or biotic stresses, except natural heat stress.

\section{Observations of recorded}

Data was recorded on 16 traits on the panel of inbreds and hybrids, including grain yield and secondary traits. Days to $50 \%$ anthesis (AD) and silking (SD) were recorded on the day when $50 \%$ plants in a plot extruded anther or produced silks. Anthesis-silking interval (ASI) was calculated as the difference between SD and AD. Leaf senescence (LS) was scored on a 1 to 10 for leaf dryness from older to younger leaves. Leaf firing (LF) and tassel blast (TB) were scored on 1-5 as the extent of leaf mortality from younger towards older leaves and for tassel mortality before anthesis, respectively. Chlorophyll content (CC) was measured using chlorophyll content meter CCM-200 (Opti-Science) and Canopy temperature Difference (CTD) was recorded using the Infra-red thermometer Agritherm III model 6110L (DIAS Infrared Systems).

At physiological maturity, observations were recorded on plant height $(\mathrm{PH})$ as the distance between the lowest node of the plant up to the node bearing tassel on five representative plants in each plot and averaged. Inter-nodal length (INL) was measured as the distance between two nodes with maximum INL, present just below the node bearing the lower-most cob. At harvest, grain yield (GY) was recorded in terms of ear weight per plot and converted to tons per hectare at $12.5 \%$ grain moisture content and $80 \%$ shelling percentage. Data was also recorded on various yield attributes, including ears per plant (EPP) as the ratio of the total ears harvested and the total number of plants in each plot, and cob girth (CG), cob length $(\mathrm{CL})$, kernels per row (KPR) and number of kernel rows per cob (KRPC) were recorded on ten representative ear in each plot and averaged to calculate these traits on per ear basis. In optimal trials, observations were recorded on all the abovementioned traits, except LS, LF, TB and CTD.

\section{Statistical analysis}

ANOVA analysis was performed using Alpha-lattice design (Patterson and Williams, 1976), using the model described below.

$$
Y_{i j k}=\mu+\operatorname{Trt}_{i}+\operatorname{Rep}_{j}+B l k_{j k}+e_{i j k}
$$


Where, $\mathrm{Y}_{i j k}$ is the response value of observed trait, $\mu$ the overall mean, $\operatorname{Trt}_{i}$ is the treatment fixed effect $(i=1,2, \ldots, n), \operatorname{Rep}_{j}$ is the replicate effect $(j=1,2, \ldots, n), B^{\prime} k_{j k}$ is the block effect, and $\mathrm{e}_{i j k}$ is the error.

Broad-sense heritability was computed using the formula suggested by Lush (1949), as:

$$
h^{2}=\frac{\sigma_{g}^{2}}{\sigma_{p}^{2}} x 100
$$

Where, $h^{2}$ is the broad-sense heritability, $\sigma^{2} g$ is the genotypic variance and $\sigma^{2} p$ is the phenotypic variance.

All datasets were subjected to statistical analysis using GENSTAT software (VSN International Ltd.), while correlation coefficients were estimated using SAS 9.2 (SAS Institute, Cary, NC, USA).

The principal component analysis (PCA) was performed using GGE bi-plot software (Yan, 2001). Prior to bi-plot analysis and singular value decomposition for evaluation of genotypes across environments, data centering (centering $=2$ ) and scaling (scaling $=0$ ) was performed. The genotype-metric preserving method for singular value decomposition was finally used $(S V P=1)$ for genotype $x$ environment interaction for grain yield and instability indices estimated for each genotype (Yan et al., 2007). To determine the traits influencing grain yield under heat stress a panel of hybrids was selected with high instability index for grain yield across environments. The genotype by traits bi-plot was constituted by scaling for standard deviation for traits (scaling =1) and trait metric preserving (SVP $=2)$ with data centering (centering $=2$ ) to obtain genotype, genotype $x$ environment interaction for the traits analysed (Yan and Tinker, 2006).

\section{Conclusion}

Genotypic variability exists in tropical maize for heat stress tolerance, though at a low frequency. Selection on the basis of stress-adaptive secondary traits along with grain yield under stress may help in identifying genotypes with improved-stable performance under heat stress. Identified stress tolerant entries possessing stress adaptive traits along and respectable grain yield under stress could be used in breeding programs targeting heat stress agro-ecologies to develop a new generation of heat stress resilient maize cultivars with enhanced tolerance to heat stress. Determining genomic regions involved and gene action for stress-adaptive traits might further help breeders use them in their breeding programs to identify and develop heat stress tolerance maize cultivars.

\section{Acknowledgements}

The financial support from United State Agency for International Development (USAID) is gratefully acknowledged. The authors are thankful to ICRISAT for providing the farm facilities and support in conducting the field trials.

\section{References}

Alam MA, Seetharam K, Zaidi PH, Dinesh A, Vinayan MT, Nath UK (2017) Dissecting heat stress tolerance in tropical maize (Zea mays L.). Field Crops Res. 204:110-119.
Apel K, Hirt H (2004) Reactive oxygen species: metabolism, oxidative stress, and signal transduction. Annual Rev. Plant Biol. 55:373-399.

Araus JE, Slafer GA, Royo C, Serrey MD (2008) Breeding for yield potential and stress adaptation in cereals. Plant Sci. 27:377-412.

Balota M, Payne WA, Evett SR, Lazar MD (2007) Canopy temperature depression sampling to assess grain yield and genotypic differentiation in winter wheat. Crop Sci. 47: 1518-1529.

Banziger M, Lafitte HR (1997) Efficiency of secondary traits for improving maize for low-nitrogen target environments. Crop Sci. 37:1110-1117.

Banziger M, Damu N, Chisenga M, Mugabe F (1999) Evaluating the drought tolerance of some popular maize hybrids grown in sub-Saharan Africa. In: CIMMYT (International Maize and Wheat Improvement Center), EARO (Ethiopian Agricultural Research Organization). 1999. Maize Production Technologies for the Future: Challenges and Opportunities. Proceedings of the Sixth Eastern and Southern Africa Regional Conference. Ethopia September, 1998.

Betran FJ, Beck D, Banziger M, Edmeades GO (2003) Secondary traits in parental inbreds and hybrids under stress and non-stress environments in tropical maize. Field Crop Res. 83:51-65.

Borrell AK, Hammer GL, Andrew CL (2000) Does maintaining green leaf area in sorghum improve yield under drought? I. Leaf growth and senescence. Crop Sci. 40:1026-1037.

Cairns JE, Sonder K, Zaidi PH, Verhulst N, Mahuku G, Babu R, Nair SK, Das B, Govaerts B, Vinayan MT, Rashid Z, Noor JJ, Devi P, San Vicente F, Prasanna BM, Donald LS, (2012)Maize Production in a Changing Climate: Impacts, Adaptation, and Mitigation Strategies. Adv Agron. 114:158.

Cicchino M, Edreira JIR, Otegui ME (2010a) Heat stress during late vegetative growth of maize: Effects on phenology and assessment of optimum temperature. Crop Sci. 50:1431-1437.

Cicchino M, Edreira JIR, M Uribelarrea, Otegui ME (2010b) Heat stress in field-grown maize,response of physiological determinants of grain yield. Crop Sci. 50:1438-1448.

Commuri PD, Jones RJ (2001) High temperatures during endosperm cell division in maize: A genotypic comparison under in vitro and field conditions. Crop Sci. 41:1122-1130.

Dass S, Singh I, Parihar CM, Kual J, Singode A, Singh DK (2010) Abiotic stressess in maize:Some issues and solutions. In. Indian Maize (ed.) Directorate of Maize Research Pusa Campus, New Delhi.

Duke ER, Doehlert DC (1996) Effects of heat stress on enzyme activities and transcript levels in developing maize kernels grown in culture. Environ Exp Bot. 36:199-208.

Duncan RR, Bockholt AJ, Miller FR (1981) Descriptive comparison of senescent and non-senescent sorghum genotypes. Agron J .73:849-853.

Dupuis I, Dumas C (1990) Influence of temperature stress on in vitro fertilization and heat shock protein synthesis in maize (Zea mays L.) reproductive tissues. Plant Physiol. 94, 665-670.

Edmeades GO, Bolanos J, Hernandez M, Bello S (1993) Causes for silk delay in a lowland tropical maize population. Crop Sci. 33, 1029-1035. 
Edmeades GO, Bolanos J, Banziger M, Ribaut JM, White JW, Reynolds MP, Lafitte HR (1998) Improving crop yields under water deficits in the trpoics. In: V.L. Chopra, R.B. Singh, A.Varma (Eds.) Crop productivity and sustainabilityshaping the future. 2nd International crop science congress. New Delhi,1998.

FAO (2016) FAOSTAT. Food and Agriculture Organization of the United Nations, Rome, Italy.

Frova C, Portaluppi P, Villa M, Goria MS (1995) Sporophytic and gametophytic components of thermotolerance affected by pollen selection. J Hered. 86:50-54.

Hunter RB, Tollenaar M, Breuer CM (1977) Effects of photoperiod and temperature on vegetative and reproductive growth of a maize (Zea mays) hybrid. Can J Plant Sci. 57:1127-1133.

Karim MA, Fracheboud Y, Stamp P (2000) Effect of high temperature on seedling growth and photosynthesis of tropical maize genotypes. J Agron Crop Sci. 184:217-223.

Kumari M, Singh VP, Tripathi R, Joshi AK (2007) Variation for staygreen trait and its association with canopy temperature depression and yield traits under terminal heat stress in wheat. In. Buck H.T., Nisi J.E., Salomón N. (eds) Wheat Production in Stressed Environments.Springer, Dordrecht 12.

Liu X, Huang B (2000) Heat stress injury in relation to membrane lipid peroxidation in creeping bentgrass. Crop Sci. 40:503-510.

Lobell, DB, Schlenker W, Costa-Roberts J (2011a) Climate trends and global crop production since 1980. Science 333:616-620

Monjardino P, Smith AG, Jones RJ (2005) Heat stress effects on protein accumulation of maize endosperm. Crop Sci. 45:1203-1210.

Nesmith DS, Ritchie JT (1992) Shortand longterm responses of corn to a pre-anthesis soil water deficit. Agron J. 84:107-113

Ober ES, Bloa ML, Clark CJA, Royal A, Jaggard KW, Pidgeon JD (2005) Evaluation of physiological traits as indirect selection criteria for drought tolerance in sugar beet. Field Crops Res. 91:231-249.

Passioura JB (1996) Drought and drought tolerance. Plant Growth Reg. 20:79-83

Patterson, HD., Williams, ER(1976) A new class of resolvable incomplete block designs. Biometrika 63, 83-92.

Patterson HD, William ER, Hunter EA (1978) Block designs for variety trials. J. Agric. Sci. 90: 395-400.

Ram M, Singh RM, Agrawal RK (2014) Genetic analysis for terminal heat stress in bread wheat (Triticum aestivum $L$. ). The Bioscan. 2:771-776.

Rattalino E, Carpici EB, Sammarro D, Otegui ME (2011) Heat stress effects around flowering on kernel set of temperate and tropical maize hybrids. Field Crops Res. 123:62-73.
Rincon-Tuexi JA, Lopez-Santillan CNS (2006) High temperature and water stress during flowering in tropical corn populations. Phyton. 75:31-40.

Rosenow DT, Clark LE (1981) Drought tolerance in sorghum. In: Loden HD and Wilkinson D (eds). 36th Annual Corn and Sorghum Industry Research Conference Chicago, December 1981.

Schoper JB, Lambert RJ, Vasilas BL (1987) Pollen viability, pollen shedding, and combining ability for tassel heat tolerance in maize. Crop Sci. 27:27-31.

Shabala S (1996) Leaf temperature kinetics measure plant adaptation to extreme high temperatures. Funct Plant Biol. 23:445-452.

Singletary GW, Banisadr R, Keeling PL (1994) Heat stress during grain filling in $\mathrm{m}$ aize, effects on carbohydrate storage and metabolism. Aust J Plant Physiol. 21:829-841.

Stebbins C (2011) Crop scientists now fret about heat not just water. Scientific American. Retrieved 19 November 2011.

http://www.scientificamerican.com/article.cfm?id=cropscientists-now-fret-about.

Suwa R, Hakata H, Hara H, El-Shemy HA, Adu-Gyamfi JJ, Nguyen NT, Kanai S, Lightfoot DA, Mohapatra PK, Fujita K (2010) High temperature effects on photosynthate partitioning and sugar metabolism during ear expansion in maize (Zea mays L.) genotypes. Plant Physiol Biochem. 48:124-130.

Tesfaye K, Zaidi PH, Gbegbelegbe S, Boeber C, Rahut DB, Getaneh F, Seetharam K, Erenstein O, Stirling C (2016) Climate change impacts and potential benefits of heattolerant maize in South Asia. Theor Appl Climatol. 130: 959-970.

Uhart SA, Andrade FH (1995) Nitrogen deficiency in maize: I. Effects on crop growth, development, dry matter partitioning, and kernel set. Crop Sci. 35:1376-1383.

Wilhelm EP, RE Mullen, PL Keeling, GW Singletary (1999) Heat stress during grain filling in maize,effects on kernel growth and metabolism. Crop Sci. 39:1733-1741.

Yan W (2001) GGE Biplot - A windows application for graphical analysis of multi-environment trial data and other types of two-way data. Agron J. 93:1111-1118.

Yan W, Tinker NA (2006) Biplot analysis of multienvironment trial data,principles and application. Can J Plant Sci. 86:623-645.

Yan W, Kang MS, Ma B, Woods S, Cornelius PL (2007) GGE biplot vs. AMMI analysis of genotype -by- environment data. Crop Sci. 47:641-653.

Yu LH, Bao PJ, Qiuzhi Z, Lu Z (2002) Study on variation of physiological indices of maize leaves near the cob at different periods. J Maize Sci. 10:32-34. 